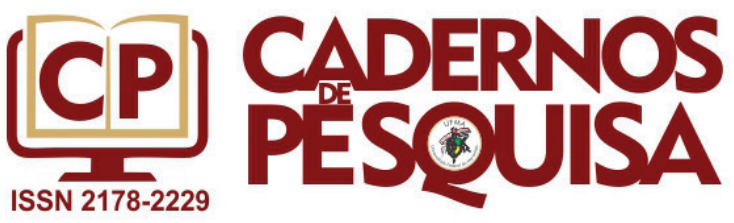

ISSN 2178-2229

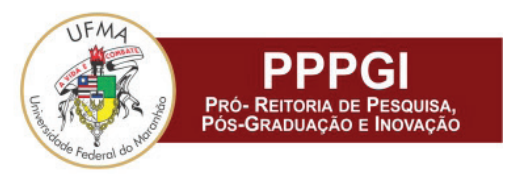

DOl: http://dx.doi.org/10.18764/2178-2229.v26n3p49-67

PROCESSOS DE ABSTRAÇÃO E AS NOÇÕES SOCIAIS DE

GUERRA E PAZ: um estudo com jovens estudantes brasileiros

PROCESSES OF ABSTRACTION AND THE SOCIAL NOTIONS OF

WAR AND PEACE: a study with young brazilian students

PROCESOS DE ABSTRACCIÓN Y LAS NOCIONES SOCIALES DE

GUERRA Y PAZ: un estudio con jóvenes estudiantes brasileños

Eliane Giachetto Saravali ${ }^{1}$

Francismara Neves de Oliveira²

\begin{abstract}
RESUMO
Tomando por referência os resultados dos principais estudos a respeito da construção do conhecimento social realizados no Brasil e no exterior, o artigo apresenta uma pesquisa que investigou a evolução na construção desse tipo de conhecimento e no desenvolvimento cognitivo em participantes brasileiros. Tratase de um estudo descritivo, de abordagem qualitativa e quantitativa, pautado no método clínico-crítico piagetiano. Foram participantes 30 sujeitos de 15, 18 e 21 anos de escolas da rede pública estadual e de uma Universidade Pública do interior do estado de São Paulo, matriculados em cursos da área de Humanas. A compreensão sobre guerra e paz foi a noção social investigada, cotejada com a prova do mecanismo da abstração reflexionante, avaliado por meio da construção de relações espaciais. Os resultados indicaram um atraso nas respostas dos participantes em relação aos encontrados em pesquisas internacionais, bem como a dificuldade existente na elaboração de um raciocínio menos aparente e mais contextualizado e argumentativo. As correlações entre a construção do conhecimento social e a abstração reflexionante foram positivas, indicando a necessidade de desenvolvimento cognitivo para se atingir níveis mais elaborados de compreensão do mundo social.
\end{abstract}

Palavras-chave: Abstração reflexionante. Desenvolvimento cognitivo. Conhecimento social. Teoria piagetiana.

\begin{abstract}
Taking as a reference the results of the main studies carried out in Brazil and abroad on the construction of social knowledge, this article presents a research that investigated the evolution in the construction of this type of knowledge and in the cognitive development in Brazilian participants. Integrating quantitative and qualitative approaches, this is a descriptive study based on the Piagetian clinical-critical method, in which participated 30 students among 15, 18 and 21 years old from state public schools as well as from a Public University, enrolled in courses in Humanities, both from the interior of the state of São Paulo. The understanding of war and peace was the investigated social notion in comparison with the construction of reflective abstraction, which is an essential mechanism for cognitive development, through the application of surfaces and perimeters' proof. The results indicated a delay in the responses of our participants in relation to those found in international researches, as well as the difficulty in developing a less apparent and more contextualized and argumentative reasoning. Likewise, the correlations between the construction of social knowledge and the reflective abstraction were positive, indicating the need for cognitive development to more elaborated levels of understanding of the social world.
\end{abstract}

Keywords: Reflective abstraction. Cognitive Development. Social knowledge. Piagetian theory.

\footnotetext{
Universidade Estadual Paulista “Julio de Mesquita Filho" (UNESP). Marilia-SP, Brasil. ORCID: http://orcid.org/0000-0003-1259-6027 E-mail: eliane.g.saravali@unesp.br.

2 Universidade Estadual de Londrina (UEL). Londrina-PR, Brasil. ORCID: https://orcid.org/0000-0002-0809-2304 E-mail: francis.uel@gmail.com
}

Artigo recebido em maio de 2018. Aprovado em agosto de 2019.

Cad. Pesq., v. 26, n. 3, jul./set., 2019. 


\section{RESUMEN}

Tomando por referencia los resultados de los principales estudios sobre la construcción del conocimiento social llevados a cabo no sólo en Brasil, sino también en el exterior, el artículo presenta una investigación sobre la evolución de la construcción de este tipo de conocimiento y sobre el desarrollo cognitivo en participantes brasileños. Se trata de un estudio descriptivo, con un enfoque cualitativo y cuantitativo, basado en el método clínico-crítico piagetiano con la participación de 30 sujetos entre 15, 18 y 21 años que asisten a escuelas públicas de la red del estado y que cursan carreras en el área de humanidades en una Universidad Pública del interior del estado de São Paulo. La comprensión sobre la guerra y la paz fue la noción social investigada, cotejada con la construcción de la abstracción reflexionante, mecanismo clave del desarrollo cognitivo, mediante la aplicación de la prueba de las superficies y perímetros. Los resultados indicaran un retraso con respecto a las respuestas de nuestros participantes si los comparamos con investigaciones internacionales. bien como la dificultad existente en a la elaboración de un raciocinio menos evidente y más centrado en el contexto y en la argumentación. Las correlaciones entre construcción del conocimiento social y la abstracción reflexionante han sido positivas y indicando la necesidad del desarrollo cognitivo para niveles más complejos de comprensión del mundo social.

Palabras Clave: Abstracción reflexionante. Desarrollo Cognitivo. Conocimiento social. Teoria piagetiana.

\section{INTRODUÇÃO}

O artigo apresentado está ancorado no aporte teórico metodológico da Epistemologia Genética Piagetiana, segundo o qual há diferenciação de três tipos de conhecimento: o físico, o lógico-matemático e o social. A elaboração do conhecimento que se dá a partir da ação física do sujeito sobre o objeto de conhecimento define sua dimensão física e "[...] consiste em agir sobre os objetos e descobrir as propriedades por abstração empírica, partindo dos próprios objetos. Por exemplo: pesar os objetos e verificar que os mais pesados nem sempre são os maiores" (PIAGET, 1978, p. 39). À dimensão física, relaciona-se a abstração empírica.

O segundo tipo de conhecimento é o conhecimento lógico-matemático, que "consiste, por sua vez, em agir sobre os objetos, mas, no caso, em descobrir as propriedades por abstração a partir não dos objetos como tais, mas das próprias ações que se exercem sobre esses objetos" (PIAGET, 1978, p. 39). Envolve, por sua vez, a abstração reflexionante, ou seja, "[...] enquanto o conhecimento físico é abstraído dos próprios objetos, o lógico matemático, ao contrário, é abstraído das coordenações das ações que o sujeito exerce sobre os objetos" (ASSIS, 2013, p. 79). Está relacionado, portanto, a coordenações internas de ações e é mais complexo que o conhecimento físico.

O terceiro tipo é o conhecimento social, resultante das transmissões culturais, produzido a partir dos contextos sociais e transmitido aos sujeitos por meio de sua interação com o mundo (ENESCO et al., 1995). Este tipo de conhecimento está diretamente relacionado às significações que permitem aos sujeitos o conhecimento de si e dos outros, bem como se refere ao funcionamento da realidade social.

A distinção entre os tipos de conhecimento, de fato, é didática, já que as relações entre os mecanismos e processos que explicam o desenvolvimento na perspectiva piagetiana supõem relações de interdependência entre os domínios (PIAGET, 1996). Assim, nenhum conhecimento pode ser puramente físico ou social visto que as relações integradoras e interdependentes explicam a produção da inteligência lógica e a coordenação de relações lógicas, por sua vez, possibilita pensar o objeto de conhecimento socialmente significado. Concordamos com Delval (2007) que todo conhecimento lógico tem sua origem nas interações sociais.

Quando estes temas são abordados é freqüente que se produza uma confusão entre a origem do conhecimento e o seu conteúdo. Temos que manifestar, de forma inequívoca, que, em nossa opinião, todo o conhecimento tem uma origem social, que o conhecimento somente é possível vivendo em sociedade e que compartilhamos com os outros o conhecimento, tanto aquele que possui como objeto o mundo inanimado, como aquele que se ocupa dos seres vivos em geral ou dos seres humanos em 
particular. Portanto, é preciso ficar claro que todo conhecimento é social em sua origem (DELVAL, 2007, p. 56, tradução nossa).

Pesquisas que tratam da construção do conhecimento social na perspectiva piagetiana e que vêm sendo realizadas no contexto brasileiro (ARAÚJO; GOMES, 2010; MONTEIRO, 2013; MANO; SARAVALI, 2014; PIECZARKA, 2009; CANTELLI, 2000) sugerem dados diferentes daqueles obtidos junto a participantes de países europeus, como a Espanha, ou do continente americano, entre eles México e Chile (DELVAL; VILA, 2008; DENEGRI; DELVAL, 2002; DELVAL; ECHEÍTA, 1991; DELVAL, 2013; ENESCO et al., 1995). Observa-se, nos trabalhos que retratam a realidade brasileira, uma diferença importante na construção deste tipo de conhecimento, qual seja, uma dificuldade na formação de um pensamento mais elaborado acerca de temas sociais. Esta construção tem se apresentado mais tardia em relação aos participantes de outros países e continentes.

Dentre os pesquisadores que se debruçam sobre a construção do mundo social, o espanhol Juan Delval (1989; 2002; 2007; 2013) é a referência mais utilizada. Seus trabalhos explicam e apresentam o caminho que percorremos ao nos depararmos com um objeto de conhecimento advindo do campo social; e têm destacado temáticas variadas, como a origem da vida (DELVAL, VILA, 2008), o mundo econômico (DELVAL, $2002,2013)$, entre tantos outros. De maneira coerente com os postulados piagetianos, suas pesquisas indicam uma evolução das noções sobre o mundo social, demonstrando um trabalho essencial realizado pelo sujeito para além daquilo que lhe é transmitido e/ ou compartilhado socialmente.

Nestas pesquisas, Delval e investigadores que o tomam por referência analisam a construção do conhecimento sobre a sociedade conforme a existência de três níveis, assim definidos por indicarem um processo que vai transformando as ideias e agregando novos elementos, tornando o olhar sobre o social cada vez menos aparente, estereotipado e simplista e, por sua vez, mais articulado, contextualizado e argumentativo.

Ao apresentar esses níveis, Delval (2002) sugere uma idade aproximada de equilíbrio para as construções. Dessa forma, o nível I é observado em suas pesquisas até por volta dos 10 anos e caracteriza-se por crenças baseadas em aspectos aparentes e visíveis dos fenômenos sociais, sendo que há dificuldade em analisar um determinado assunto como algo mais complexo e sujeito a múltiplas influências, sejam elas conflituosas ou não. O segundo nível se apresentaria por volta dos 10 aos 13 anos e as interpretações que esses sujeitos possuem indicam uma percepção maior de processos ocultos que envolvem as questões sociais, embora ainda haja dificuldade para a obtenção de soluções. O terceiro e último nível teria seu início por volta dos 13, 14 anos, correspondendo à existência de crenças mais elaboradas, carregadas de um maior número de informações e acompanhadas da consideração de questões e interesses opostos.

Nas pesquisas realizadas no Brasil, conforme apontamos, alguns autores observam uma diferença temporal em relação a essa construção. Assim, apesar de os sujeitos estarem localizados na mesma faixa etária apontada nos estudos de Delval, os participantes dos estudos brasileiros não apresentam noções características do nível de compreensão correspondente e, por vezes, tais trabalhos indicam a ausência da elaboração de noções correspondentes ao nível III (CANTELLI, 2000; BARROSO, 2000; MONTEIRO, 2013; MANO; SARAVALI, 2014; SOUZA; SARAVALI, 2016). Não se trata de enfatizar a discrepância na idade dos participantes brasileiros, já que, na perspectiva piagetiana, a idade é considerada apenas referência e não condição suficiente para a construção do conhecimento. Entretanto esse dado revela que a evolução no progresso de compreensão de uma noção apresenta-se tardio ou com ausência de nível III na realidade brasileira.

A constatação dessa diferença nos níveis de respostas, apresentados pelos participantes brasileiros, em relação aos níveis evolutivos descritos nas pesquisas de 
Delval (2002, 2013), nos motivou a relacionar a compreensão de uma noção social e a construção de relações espaciais que ocorrem por meio da abstração reflexionante.

Um aspecto interessante que talvez possa explicar essa diferença reside nos equilíbrios que ocorrem nos sistemas cognitivos e que caracterizam a maneira como as crenças sobre o mundo social são construídas. A esse respeito, Delval (2007), primeiramente, delimita que o processo de socialização não pode se traduzir somente pelas pressões externas, pela imersão na cultura ou pela conversão dos indivíduos em seres sociais. Ou seja, interessa conhecer o trabalho realizado pelo próprio indivíduo.

Nesse sentido, um dos primeiros elementos a destacar refere-se à aquisição das normas ou regras que normatizam a vida no contexto social. Delval (2007, p. 60, tradução nossa) esclarece: "Estes elementos determinam o que deve ser feito e referem-se a como devem ser as ações, e não a como elas são". Para além desses elementos, o autor elucida que, na construção do conhecimento social, precisamos receber informações sobre fatos concretos do mundo social e isso provém dos outros e a partir das próprias ações ou interações sobre e com o meio. Apoiados nesses elementos, os sujeitos elaboram explicações sobre o funcionamento e a organização dos sistemas sociais.

No nível III de compreensão da realidade social, são requeridas explicações que fazem apelo à interpretação que o sujeito consegue realizar a partir das noções e informações sobre as quais age. Sendo assim, a interpretação explicitada pelo sujeito revela interação entre os dois polos da relação sujeito-meio, uma vez que o sujeito age sobre o meio e com ele interage. Aspectos normativos e informativos fazem pouco sentido quando não são alvo de reflexão, inseridos ou mesmo em relação a aspectos e fenômenos mais complexos. Nesse sentido, a análise do que caracteriza o nível II indica que é possível ao sujeito permanecer no âmbito da informação que não se articula com explicações mais profundas. Esses mesmos sujeitos tampouco conseguem encontrar resoluções possíveis para problemas do mundo social (MANO, SARAVALI 2014; DELVAL, 2013).

Noções sociais exemplificadoras desse processo são as noções de guerra e paz. 0 fenômeno da guerra é bastante complexo e, para poder refletir a respeito, é necessário desvincular-se de questões visíveis, como armas, militares, etc., ampliando o olhar para aspectos históricos, econômicos, culturais, entre outros. A guerra é, portanto, um fenômeno que direta ou indiretamente afeta os membros de uma sociedade como um todo.

\footnotetext{
A guerra é o conflito macro por excelência, já que nela intervém uma grande multiplicidade de variáveis de caráter psicológico, social, cultural, econômico, político e normativo. Ainda que, muitas vezes, tenha sido difícil distinguir entre as causas reais e os pretextos alegados, os objetivos declarados e os não confessados, as funções aparentes e as subjacentes, as guerras não costumam responder a uma única causa, e sua análise e compreensão vão requerer, por definição, um enfoque interdisciplinar. (RAMÍREZ, 2008, p. 592, tradução nossa).
}

De igual modo, a busca pela paz ou por uma definição de paz envolve uma multicomplexidade de fatores que transpassa a simples ideia de oposição à guerra. Oporse à guerra significa considerar dimensões institucionais e não somente manifestações pessoais e unilaterais (RAMIREZ, 2008). Dessa forma, a amplitude do conceito de paz abarca a organização de medidas pela paz, bem como a oposição à violência, que é um conceito ainda mais complexo que a própria guerra.

Estudos que se preocuparam em identificar como esses conceitos sociais são compreendidos pelos sujeitos (DELVAL; DEL BARRIO, 1992; DENEGRI; DEVAL, 2002; HERNÁNDEZ, 1992; NAVARRO; ENESCO, 1993) mostram um árduo trabalho de interpretação, indicando a reação do indivíduo às informações sociais provenientes dos 
meios de comunicação, da escola, dos adultos, assim como a reorganização da própria experiência.

De uma maneira geral, observou-se que os pequenos, até por volta dos 6 , 7 anos, apresentam uma grande dificuldade em se desprender de aspectos mais figurativos e pensam a guerra de maneira anedótica, existente apenas em filmes, livros, caracterizada por armas, soldados, tiros, lutas, etc. Suas causas e desfechos dependem exclusivamente da boa vontade dos envolvidos que querem ou não a guerra. A paz é interpretada de maneira literal: dormir em paz, permanecer em silêncio, etc. Como este tipo de interpretação está muito afastado do real, não é possível conceber as consequências dos diferentes fenômenos (DELVAL, DEL BARRIO, 1992).

Por volta dos 10-11 anos, inicia-se o desprendimento da aparência e novos elementos aparecem nas explicações infantis, tais como conflitos religiosos, políticos, econômicos. No entanto, as soluções para esses conflitos permanecem ainda dependentes do diálogo entre as pessoas. A paz está associada à ausência de guerra, com referência a alguns personagens históricos que lutam/lutaram por ela.

Em torno dos 14-15 anos, percebe-se que o fenômeno é analisado com base em acontecimentos históricos e processuais e o caráter estereotipado e reducionista das explicações perde força. A esse respeito, Delval e Del Barrio (1992, p. 171, tradução nossa) explicam:

\begin{abstract}
Acreditamos que uma compreensão completa do fenômeno da guerra em todos os seus aspectos e com todos os matizes que possuem um conflito social não é possível até a adolescência, quando se desenvolve a capacidade de um pensamento mais abstrato, entre outras coisas, porque é necessário compreender a dimensão da mudança histórica que, como sabemos por inúmeros trabalhos, requer poder manejar conceitos acerca do possível e dar-se conta de que as sociedades não são sempre iguais, mas que evoluíram, muitas vezes, por meio de conflitos, de desvios e de rupturas.
\end{abstract}

Considerando o exposto, a presente pesquisa ${ }^{3}$ se desenvolveu na perspectiva de compreender melhor a construção do conhecimento social no contexto brasileiro, em especial a constituição do nível III, por meio das respostas de nossos participantes às questões propostas numa entrevista clínica envolvendo a noção de guerra e paz, cotejadas com o desempenho na prova operatória das relações entre as superfícies e perímetros. Por isso, privilegiamos sujeitos adolescentes, porém mais velhos que aqueles usualmente pesquisados, e também adultos, estudantes de uma Universidade Pública de cursos da área de Humanas, onde as discussões e a necessidade de reflexão acerca de fenômenos sociais são frequentemente requeridas.

Interessou-nos, portanto, observar as crenças sobre a guerra e a paz em sujeitos brasileiros mais velhos do que os participantes das pesquisas nacionais e internacionais, bem como relacionar essas crenças com os processos de abstração.

Piaget nos apresenta dois tipos de abstração, a empírica e a reflexionante; esta última subdividida pelo autor em pseudoempírica e refletida. A abstração empírica permite a retirada de características observáveis dos/nos objetos e a abstração reflexionante atua por intermédio das coordenações das ações dos sujeitos. A abstração pseudoempírica consiste numa variação da abstração reflexionante, porém apoiada nos resultados constatáveis da ação, e a abstração refletida é uma abstração reflexionante que se torna consciente ao sujeito (PIAGET, 1995).

Quando Piaget nos apresenta o mecanismo de abstração reflexionante, atribui ao mesmo o caráter de motor do desenvolvimento cognitivo e um dos aspectos mais gerais do processo de equilibração (PIAGET, 1995). Assim, para o autor, tal abstração não se apóia apenas em objetos físicos ou elementos materiais da própria ação, mas sobre as atividades cognitivas do sujeito. A abstração reflexionante é composta, portanto, de

Financiada pela CAPES

Cad. Pesq., São Luís, v. 26, n. 3, p. 49-67, jul./set., 2019. 
dois processos: o reflexionamento (réfléchissement) e a reflexão (réflexion); o primeiro projeta para um plano superior aquilo que retira do precedente e o segundo permite a reconstrução ou reorganização desse novo elemento, agora situado no novo plano.

Ainda na mesma obra, Piaget admite que esse processo ocorre em todos os períodos do desenvolvimento, mas que, quando estivermos tratando do pensamento formal ou "[...] quando a reflexão é obra do pensamento, faz-se necessário distinguir também seu processo enquanto construção de sua temática retroativa, que se torna, então, uma reflexão sobre a reflexão: falaremos neste caso de 'abstração refletida' (réfléchie) [...]" (PIAGET, 1995, p. 6). Esse mecanismo fundamental permite a criação de novidades e o enriquecimento de formas, uma vez que sua atuação ocorre justamente nas coordenações dos elementos, das informações.

\begin{abstract}
O primeiro resultado das abstrações reflexionantes é, portanto, acarretar, seja a diferenciação de um esquema de coordenação para aplicá-lo de maneira nova, o que aumenta os poderes do sujeito [...], seja a "objetivação" de um processo coordenador que se torna, então, objeto de representação ou de pensamento, o que aumenta os conhecimentos do sujeito, alargando o campo de sua consciência e enriquecendo, portanto, sua conceituação (PIAGET, 1995, p. 278).
\end{abstract}

Esse caráter criador e de acréscimo de novidades nos faz acreditar que o avanço na construção desse mecanismo traria ao sujeito condições mais favoráveis de compreensão de fenômenos sociais, dentre eles uma noção complexa como a de guerra e paz. O nível III corresponderia a uma crença que coordena diferentes elementos, que analisa as situações possíveis e as existentes, que considera diferentes possibilidades de solução, envolvendo o exercício dos papéis sociais. A abstração reflexionante é, portanto, uma construção importante para a interpretação que o sujeito faz da realidade social.

\title{
2 METODOLOGIA
}

Trata-se de um estudo descritivo, de abordagem qualitativa e quantitativa, pautado no método clínico-crítico piagetiano (PIAGET, 1967, 1979). Participaram 30 sujeitos de 15, 18 e 21 anos, sendo $50 \%$ do gênero masculino e $50 \%$ do gênero feminino, de escolas da rede pública estadual e de uma Universidade Pública do interior do estado de São Paulo, matriculados em cursos da área de Humanas. A amostra foi composta por conveniência e a escola participante localiza-se num bairro periférico do município, atendendo população de baixa renda. Os alunos de 15 anos estavam regularmente matriculados no primeiro ano do ensino médio, os demais estavam no primeiro e quarto ano do ensino superior.

Em todas as etapas da pesquisa foi utilizado o método clínico-crítico piagetiano (PIAGET, 1967, 1979), que tem por característica desdobramentos de uma questão em outras não programadas, permitindo maior aproximação dos meandros do pensamento e da forma como a resolução de desequilíbrios e conflitos ocorre. Além disso, tratase de um método apropriado para pesquisas ancoradas no referencial teórico da Epistemologia Genética.

Os procedimentos metodológicos aplicados junto aos participantes foram: 1) entrevista clínica sobre as noções de guerra e paz (DELVAL; DEL BARRIO, 1992); 2) prova das relações entre superfícies e perímetros dos retângulos (PIAGET, 1995).

$\mathrm{Na}$ entrevista clínica, os participantes puderam apresentar suas ideias a respeito das noções de guerra e paz - condições, resoluções, análise de conflitos, entre outros. A prova operatória utilizada permite avaliar as relações entre superfícies e perímetros que são construídas por meio da atuação das abstrações (PIAGET, 1995).

Os dados de ambas as entrevistas, $20 \%$ dos nossos protocolos, foram submetidos a juízes e, conforme as orientações de Fagundes (1981), foi calculado o Índice de concordância. Obtivemos um percentual de concordância de $91 \%$ em relação à 
entrevista clínica e $86 \%$ para a prova operatória; índices que garantiram a objetividade e coerência dos protocolos.

Para análise da verificação da relação entre essas variáveis - entrevista clínica e investigação da abstração reflexionante, os dados foram submetidos às correlações de Spearman, no Programa ACTION. A escolha desse teste se deu pelo fato de serem medidas de correlação não-paramétricas, ou seja, aquelas que não exigem nenhum pressuposto de teste paramétrico (distribuição normal dos dados), e por serem menos sensíveis a um número pequeno de observações.

Os sujeitos de 18 e 21 anos foram convidados a participar e, conforme se voluntariavam, recebiam informações sobre a pesquisa, assinando o Termo de Consentimento Livre e Esclarecido (TCLE). Já os participantes de 15 anos, que também se voluntariaram, receberam informações sobre a pesquisa, assinaram o Termo de Assentimento e tiveram o TCLE assinado pelos seus responsáveis.

Os procedimentos éticos da pesquisa foram analisados e aprovados pelo Comitê de Ética em Pesquisa local (processo número: 0949/2014). Todos os dados foram coletados nas respectivas instituições escolares. As entrevistas foram realizadas individualmente, em salas designadas para as pesquisadoras, gravadas em áudio e vídeo e, posteriormente, transcritas para análise.

\section{RESULTADOS}

Em nossos protocolos, observamos respostas semelhantes aos estudos citados anteriormente que se debruçaram sobre as crenças a respeito da guerra e da paz. Assim, nossos dados puderam ser interpretados conforme os três níveis de compreensão observados por Delval (2002, 2013), juntamente com Del Barrio (1992).

Embora o caráter anedótico das respostas infantis, apontados nos estudos internacionais, não esteja presente em nossos protocolos, tendo em vista que os participantes eram adolescentes e jovens adultos universitários, encontramos respostas ainda muito rudimentares. Nelas, observam-se que um fenômeno complexo como a guerra é retratado como um conflito entres países, com predomínio das relações pessoais daqueles envolvidos e/ou responsáveis pela guerra. Ainda que, nas respostas, os sujeitos possibilitam vislumbrar consequências para a guerra, visto que seu caráter inverossímil e fantasioso não foi encontrado aqui, observamos uma personificação de um ou outro país que sempre "quer ou não fazer algo" em prol ou contrário à guerra. Alguns exemplos:

ANP $\left(18 ; 10^{4}\right)$ : Quais os motivos que poderiam levar a ocorrer uma guerra? Por exemplo, às vezes, um presidente tem interesses econômicos naquela terra e o outro presidente não concorda. Ele fala "não, aqui é o meu país, se você quiser fazer uma aliança alguma coisa do tipo nós fazemos", mas o outro não concorda "bom eu vou tomar isso de qualquer jeito" e aí vai acontecer uma guerra. E como ela começa? Brigas. Brigas como? Discussões, briga entre pessoas mesmo, igual a gente estava falando de países, tipo um presidente brigar com o outro. Eles tiveram uma discussão e um declarou guerra pro outro assim "eu vou brigar com seu país". E aí eles brigam. Você acha que uma guerra pode acabar? Sim. Como? Eu acredito que uma guerra acaba quando um ganha e o outro perde. Se eles estão em conflito um vai ganhar o outro vai perder e aí vai acabar. E como é isso de um ganhar e o outro perder? Como que é isso? Esse ganho e essa perda? Igual a gente estava falando, eu sou do Brasil e eu quero tomar... sei lá, a Argentina. Aí eu não me bato bem com o presidente, falo: "eu vou brigar, eu quero a Argentina e acabou", aí eu mando militares, aí tem aquela coisa de tiros, bombas, um monte de coisa e aí, por exemplo, a minha tropa ganhou da tropa da Argentina. Aí eu tenho a minha terra e Argentina perdeu, eu tomei o país deles. Como a tropa ganhou? Como é isso, como se diz que a tropa ganhou? Pela

Assim como nos protocolos piagetianos, entre parênteses estão a idade dos participantes em anos e meses, respectivamente.

Cad. Pesq., São Luís, v. 26, n. 3, p. 49-67, jul./set., 2019. 
guerra, por exemplo eu posso ter mais militares que eles. Posso ter mais armas que eles, posso ter matado todo mundo lá e eu ganhei.

MAI (18;11): Uma guerra é uma, guerra é guerra; ah, eu não sei explicar o que é uma guerra, é uma... sei lá... uma batalha entre dois países, mas que envolve muitas pessoas, e sempre um lado vai perder, alguém tem que ganhar e aí muitas pessoas vão morrer... as que estão lutando por este país. Como que ela começa, então, a guerra, como você acha que ela se inicia? Quando eles tentam assim, eles tentam de várias maneiras eu acho que eles tentam chegar a um acordo através de cartas, sei lá alguma coisa, e eles não conseguem, e aí o outro país vê que ele tem condições de iniciar uma guerra... Se ele vê que não vai perder. Ninguém começa uma guerra achando que vai perder, se acha que ele tem condições, ele começa uma guerra contra o outro. Aí ele começa a guerra e o outro tem que aceitar, porque senão ele vai, sei lá, vai ser bombardeado vai morrer todo mundo no país dele, todos os soldados.... Aceitar o que? A guerra que o outro começou, porque assim acho que não são os dois que querem a guerra, sempre começa com um país que decide começar a guerra, só que aí o outro tem que se... ele tem que criar uma barreira, algum jeito dele se defender, então ele também acaba entrando na guerra. Você acha que sempre tem um que está se defendendo e o outro está atacando? Sim. Sempre? Sim sempre, eu acho que sim. Você acha que poderia ser feita alguma coisa para que nunca houvesse guerras? Ou dito de outro jeito, tem alguma forma de se evitar as guerras? Eu acho que não, porque sempre vai ter alguma coisa que o outro tem que você vai querer, assim tem coisas que não tem pra todo mundo, sempre ele vai ter aquilo que você vai querer e aí você vai ter que começar uma guerra, às vezes as guerras são por motivos muito banais, aliás eu acho que não tem como evitar. Por exemplo, uma guerra por motivo banal, como assim? Não sei muito bem de guerra, às vezes, dos Estados Unidos querer invadir tal lugar lá no Iraque, essas coisas e acabou matando um monte de crianças, mas eles invadem, só por... pra procurar alguém ou pra sei lá, querer o armamento ou alguma coisa, não tem sentido, é igual de território quando teve da Rússia, não sei o que eles queriam... tal parte que estava em tal país, não tem pra quê fazer uma guerra, pegasse tudo e dividisse tudo igualzinho para todo mundo e aí ficasse tudo igual, não tem como.

A análise que esses sujeitos conseguem realizar é uni fatorial. Do ponto de vista da compreensão, não se percebe, na fala deles, uma visão de conjunto, tal como explorada por Piaget quando analisa o nível mais elaborado das construções cognitivas (III), em sua obra Formas Elementares da Dialética (1996). Os sujeitos aqui enfatizam relações entre as partes, mas não construíram a totalidade e a interdependência entre elas. De igual forma, percebemos que a paz é tratada como dependente da boa vontade e intenção dos líderes envolvidos, como evidenciam os excertos a seguir:

NAT (18;11): O que é preciso para se ter paz? Eu vou dar um exemplo de dois países, Estados Unidos, que é briguento, e Rússia, são países diferentes, populações diferentes, linguagens diferentes, são culturas diferentes. Aí eu acho que é onde entra a paz, mesmo com toda diferença eles saibam respeitar a cultura deles. Se a Rússia tem um formato político e os Estados Unidos têm outro, porque ele tem que recusar o modelo político, o dele é tão melhor assim? Então se ele crê que o dele é tão melhor, então porque ele não tenta conversar mais? A Rússia não é obrigada a mudar sua política porque o outro não gosta, se ele não gosta o problema é dele, ele cuida da organização dele. Agora eu acredito que a paz é isso, você não interferir numa coisa que não te diz respeito a você, eu acho que é assim, eu acho por isso dá pra ter paz entre dois países, duas culturas tão diferentes, é que nem a gente querendo... tem muita coisa que é feita na África que a gente é contra, extremamente contra, dá para interferir? 
FRA (21;8): E você acha que teria alguma forma de se evitar as guerras? Acho que sim, se as pessoas fossem mais humanas, sei lá, assim tentassem entender o outro, a situação do outro, ajudar também quando precisa.

As respostas que foram consideradas como de nível II começam a apresentar novos elementos. As explicações para as causas e as consequências de uma guerra podem se ampliar, oferecendo-se razões menos pessoais e subjetivas (embora estas ainda permaneçam). Dessa forma, aparecem os conflitos territoriais e os interesses econômicos. Observa-se a transição entre o pensamento fantasioso, predominado pelas experiências pessoais, para aquele que passa a considerar as relações de poder, as forças políticas, os processos ocultos e históricos, mais lentos, tornando o mundo menos estático. Alguns sujeitos conseguem apontar questões não visíveis de conflitos como, por exemplo, a guerra fria, as consequências psicológicas para os habitantes dos países em guerra, etc. A referência única em relação à vontade das pessoas para a resolução de conflitos diminui. A guerra pode ser vista como aquilo que acontece longe (entre países distantes) ou bem próximo (entre pessoas, etc.).

A paz passa a ser a ausência de guerra e esta se finda mediante acordos que dependem ainda da vontade e da colaboração de algumas pessoas interessadas. Entretanto é vista como algo que necessita ser negociado na forma de tratados e acordos mútuos. Alguns exemplos:

ALI (15;8): A guerra pra mim... eles estão brigando por algum motivo, espaço, direito ou próprio território. Mais algum motivo? Sim, por algum direito, acho que por tudo está tendo guerra. Você falou pra mim "eles", quem seriam esses eles? Eles, no caso de direito, seriam todos nós e... acho que entre alguns motivos vão mudando as pessoas, tem a questão de território, você sabe que o que tá acontecendo, em guerra assim na Palestina eles estão brigando entre eles pra conseguir um espaço, agora, por direitos, é a gente, a nação tentando conseguir direitos iguais. [...] Depois que a guerra começa você acha que tem como ela terminar? Tem. Como? Entre os dois lados que têm a guerra, e pra ter o final as duas partes têm que estar igual decididas, entrar em comum acordo. E como seria isso? Entre guerra de território, divide, acho que assim, a gente quando quer muita coisa para a gente, a gente acaba não tendo nada, então a gente teria que... o que eu penso na guerra da Palestina, que eles teriam que criar o país Palestina, né, e acabar com a guerra, acho que o término seria um acordo entre os dois lados. Em toda e qualquer guerra? Ou só nesse caso específico? Qualquer guerra. O que é preciso para que a paz exista? Acordo, acordo, ter comunicação, porque, assim, se um país quer ter paz com o outro, eles têm que se comunicar, igual tem país que vai e invade o outro só pra ver como que eles governam, como é que eles tratam o dinheiro, então eu acho que a paz é isso, não invadir, mas ter essa comunicação de falar, de trocar ideias.

KET (18;8): Quais são os motivos que levariam a ocorrer uma guerra? Guerra mundial? Por que você está me perguntando? Porque sei lá, por exemplo, uma guerra mundial seria países entrando em conflito ou uma guerra aqui já seria outra coisa. Então me fala dos diferentes tipos. Acho que uma guerra mundial é quando, ah esse negócio de posses ou então um país está devendo para o outro, é isso, uma guerra mundial seriam esses os problemas, problemas econômicos, o maior motivo é dinheiro, né, então é isso. Agora uma guerra menor, acho que muita coisa, qualquer coisa vira guerra, dependendo se não tentar conversar. Me dá um exemplo. Uma guerra pequena, ah não sei, tipo sem terras, por exemplo, quando eles invadem a terra existe um conflito entre eles e a polícia, aí, acaba acontecendo guerra por falta de conversa, por medir as forças para ver quem é o melhor pra conseguir ficar com aquilo que se deseja. Isso seria uma guerra? Sim. Tem algum outro tipo de guerra, além dessas que você falou? Entre países, entre as pessoas, além dessas? Sim, além dessas que você falou. Não sei acho que não.

JUC $(21 ; 5)$ : Quais são os motivos que levariam a ocorrer uma guerra? Dinheiro. Como assim? A maioria das guerras, elas acontecem por interesses 
econômicos mesmo, um país que tem petróleo, o outro... quer o petróleo daquele país, então vai lá e ataca, então acho que a maioria das guerras é por questões econômicas, e religiosas também. Como seriam as religiosas? Um país, por exemplo, tem uma religião, o outro tem outra, eles brigam assim, acho que é mais isso, questões econômicas, questões religiosas ou culturais; culturas muito diferentes e acaba também um querendo que o outro se submeta à cultura dele, como na religião também, e aí isso vira guerra.

Como característica do nível II, percebe-se o reconhecimento dos conflitos, embora as soluções para eles sejam bastante limitadas. Os sujeitos desse nível iniciam construções interdependentes no modo de explicar a guerra; conseguem, por exemplo, perceber a diferença entre conflito de interesses e guerra, admitindo que interesses contrários podem ser administrados sem que a guerra seja a única solução possível. No caso de POL (15;5), a seguir, o conflito pode existir e continuar ainda que não haja guerra.

POL (15;5): O que é a guerra? A guerra eu acho que é... a disputa entre território, não sei, um conflito. É, e quais seriam os motivos que levam a acontecer esse conflito? A disputa por território, ou uma diferença... é... seja ela cultural, religiosa ou econômica. Mais algum motivo? Ou pela superioridade também, sentimento de superioridade também leva à guerra. [...] E como é que se inicia uma guerra? Acho que, por vários motivos, pode-se começar uma guerra, sempre tem um estopim que desencadeia o resultado de todas as ações que já foram. Por exemplo: tem a disputa territorial, daí a pessoa, tipo, um país avança um pouquinho o território do outro, aí começa a guerra, foi o estopim, mas o conflito entre esses países já vinha de muito. E depois que começa, uma guerra pode acabar? Pode, se silenciar, pode acabar assim de ver, entrar num acordo de paz ali, mas talvez a guerra pode se silenciar e continuar ali um conflito, vamos dizer assim... um conflito silencioso entendeu?

ELI (15;9): E uma guerra pode acabar? Eu acho que uma guerra pode até acabar, mas a marca que ela deixa não. Como que acaba uma guerra? Eu acho que, de tanto guerrear, eles decidem... não eles, mas os países em volta - porque uma guerra não atinge só dois países e sim o mundo, dependendo das potências - eu acho que eles fazem um tratado de paz, pelo fato de que não há vencedores de guerra. Então vão perdendo os soldados, soldados, até não resistir mais; e aí os outros países se unem pra fazer o tratado de paz e cessar a guerra desses dois países. Ou então um país vem, esmaga o outro, e pega seus bens. Tem alguma situação em que você acha que a guerra é necessária? Na verdade, eu acho que o mundo, desde que o mundo é mundo, ele não vive sem guerra: sempre, de um lado ou do outro, há guerra; então, querendo ou não, acho que a guerra é necessária para o mundo. [...] E a paz, o que é a paz? A paz é quando não tem mais guerras, e os países que têm um conflito resolvem entre si, e não tem mais conflitos e nem mortes; então, se não há mortes, podemos dizer que há paz.

CAM $(18 ; 10)$ : O que você acha que é preciso fazer para se ter paz? Primeiro, o que a ONU está fazendo... não ter guerra, não ter armas, que nem tem países que tá construindo armas nucleares... proibir, eles tentam, mas eles fazem escondido, é difícil isso no caso... Ter, acho que, campanhas de conscientização, acordos de paz que têm geralmente depois da guerra, acho que essas coisas. Por que você acha que é difícil parar, fazer um país parar de se armar? Porque ele sempre vai ter uma rivalidade com outro país, ele quer estar sempre preparado, às vezes nem pra atacar, mas com medo de ser atacado. Como você não sabe o que o outro país está fazendo, você fica preparado, acho eles têm esse bloqueio de ficar preparado já, eu falo mais os Estados Unidos, porque o mundo inteiro tem raiva deles, parece. Todo mundo ataca os Estados Unidos, por exemplo, o Iraque que também faz isso, porque 
todo mundo quer atacar ele por causa de petróleo, mas às vezes não é eles que querem isso... é do mundo que eles querem proteger.

Apesar de as soluções vistas anteriormente serem ainda difíceis, visto envolverem a coordenação de diferentes perspectivas e aspectos, observa-se que, nesse nível, os sujeitos conseguem vislumbrar de maneira mais complexa as possíveis consequências para uma guerra, abandonando, aos poucos, o caráter atemporal e imediatista do nível anterior. A visão de conjunto, de contexto, de multiplicidade de fatores relacionados por interdependência começa a se estruturar para que chegue a predominar e a se constituir como característica do nível seguinte.

JES (18;11): Você acha que uma guerra pode acabar? Quando uma das partes ceder. Ela acaba quando uma das partes ceder? Acho que sim, ou quando uma das partes for exterminada ou quando uma das partes ceder às imposições do outro... Porque... eu acho difícil acabar uma guerra porque, pelo menos que eu conheço, as guerras que tiveram não é assim, "ah, acabou a guerra e pronto todo mundo desocupa o país um do outro". Não é assim, tudo acontece devagarzinho porque se um atirar no companheiro do outro lado, pronto já começa tudo de novo, qualquer "cisquinho", pronto, já vira um incêndio. O que você acha que pode acontecer quando acaba uma guerra? Muitas crises. Por exemplo? Crises familiares, porque muitas pessoas morrem, às vezes morre alguém que era responsável por manter a família, tudo fica destruído, os prédios ficam destruídos as casas ficam destruídas, aí tem que construir tudo de novo, o setor econômico do país fica muito difícil porque investe muito em armamento, investe muito na saúde para tentar curar os soldados que estão machucados, e aí se gasta muito e quando acabar a guerra não têm dinheiro pra reconstruir, não tem dinheiro para ajudar a restaurar das cinzas, restaurar do que sobrou. $\mathrm{E}$ isso acontece com todos os países que estão em guerra? Eu acho que sim, alguns, quando têm a economia mais forte estabelecida, conseguem se reestruturar mais fácil, por exemplo, o Japão, já passou por uma super guerra, tsunami, toda hora acontece alguma coisa lá, e eles tão conseguindo se recuperar. Agora, países fracos, por exemplo, o Taiti, aconteceu lá o furacão, o tsunami, eles não conseguiram se recuperar, estão lá em ruínas, ficam dependendo de água, ficam dependendo da ajuda internacional, ajuda das entidades internacionais, ficam lá em ruínas, porque não tinha uma economia sólida, no caso não foi uma guerra, mas foi... aconteceu um desastre natural, atrapalhou muito a vida deles, matou muita gente, muita gente ficou desaparecida, falta alimento, falta água, e eles estão lá.

JEQ $(21 ; 5):$ O que você acha que acontece depois que uma guerra acaba, ou quando uma guerra acaba? Assim, um vencedor entre aspas, porque ali ninguém venceu, porque todo mundo teve muita perda, então os dois lugares que se confrontaram sempre têm muita perda... passa por um período muito difícil, que começa agora cada nação que se enfrentou, de certa forma, se une para tentar se reerguer. Se reerguer em que sentido, que tipo de destruição? Assim, financeira mesmo, reconstruir os lugares que foram destruídos, conseguir de novo estabilizar seu sistema econômico, dessa forma, seria uma união entre as pessoas do país para tentar restabelecer tudo de novo.

LUA $(21 ; 9):$ O que você acha que acontece depois que uma guerra acaba? Acho que a estrutura física é abalada e a psicológica também, porque uma guerra não começa... não começou ontem e vai acabar hoje, são fatos, são por anos que acontecem, e aí as pessoas sentem a perda de familiares, a pessoa não vai esquecer aquilo, vai ficar com aquilo na cabeça... é, em algumas guerras, eles usam o estupro das mulheres como arma, então, igual na Bósnia, acho que foi; acontece isso, e aí a pessoa fica com aquele trauma psicológico, ela não consegue estabelecer uma relação com outra pessoa, acho que acontece isso. Meio que arruína a sociedade inteira. 
Em relação ao nível III, Delval e Echeíta (1991) nos explicam que é necessário compreender o predomínio dos longos processos históricos e daqueles implícitos. 0 sujeito precisa ser capaz de examinar diferentes possibilidades sistematicamente, bem como coordenar diferentes perspectivas e pontos de vista, que, muitas vezes, vão indicar que nem sempre uma solução simples e rápida é possível, já que, na interpretação do sujeito, atuam variáveis pessoais, condições históricas, crenças. $\mathrm{O}$ tempo é compreendido como um sistema de alcances diferenciados e dialeticamente interdependentes (micro e macro tempo). A guerra pode, por exemplo, ter início muito antes do tempo presente, relatando um processo sobre o qual não se tem mais controle. Em relação à paz, são mencionados os percursos e organizações voltados a isso, os direitos humanos, os processos de negociação bastante complexos, entre outros. Os sujeitos não só possuem mais informações corretas, como também conseguem integrálas num sistema coerente, dando-lhes sentido e interpretação possíveis. Nenhum dos nossos participantes apresentou respostas que pudessem ser enquadradas nesse terceiro nível.

A tabela 1, a seguir, apresenta o desempenho de nossos sujeitos, durante a entrevista sobre as noções de guerra e paz.

Tabela 1 - Desempenho dos Participantes na Entrevista sobre Guerra e Paz

\begin{tabular}{ccc}
\hline Idades & $\begin{array}{c}\text { Níveis de } \\
\text { Compreensão }\end{array}$ & Frequência absoluta \\
\hline 15 anos & I & 3 \\
15 anos & II & 7 \\
18 anos & I & 4 \\
18 anos & II & 6 \\
21 anos & I & 4 \\
21 anos & II & 6 \\
\hline Total & & 30 \\
\hline
\end{tabular}

Fonte: Elaborado pelas autoras.

A construção por abstração reflexionante foi verificada em nossa pesquisa mediante a aplicação da Prova das Relações entre Superfícies e Perímetros dos Retângulos, apresentada em Piaget (1995, Cap. 12). Tratam-se de duas situações envolvendo a variação das relações entre as áreas ou superfícies e os perímetros. Num dispositivo, doravante denominado de A (foto 1, à esquerda), nas transformações de R1 a R3 (retângulo 1 a retângulo 3 ), o perímetro $(P)$, representado pela utilização de um barbante, mantém-se constante, ao mesmo tempo em que a área (S) diminui no decorrer das transformações de 1 a 3 (T1 a T3). Num dispositivo B (foto 1, à direita), temos a inversão da situação anterior e as transformações de R1 a R3 evidenciam um aumento de $\mathrm{P}$ enquanto $\mathrm{S}$ permanece constante no decorrer das transformações T1 a T3. Na foto 1, a seguir, tem-se a apresentação dos dois dispositivos.

Fotografia 1 - Dispositivos da Prova das Superfícies e Perímetros.

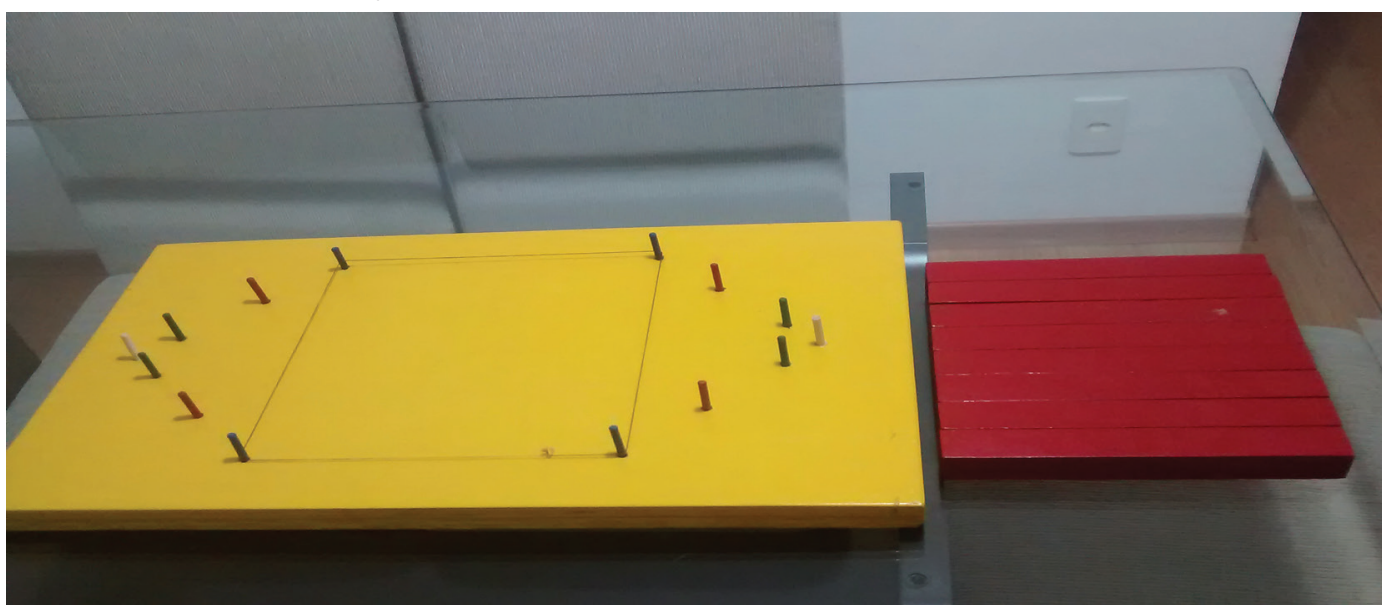

Fonte: As autoras 
De acordo com os protocolos apresentados por Piaget (1995), a construção desse mecanismo percorre níveis diferenciados, como apresentados a seguir.

No primeiro nível, ou IA, ocorrem correspondências globais entre superfície (S) e perímetro $(P)$ : ambos aumentam ou diminuem ao mesmo tempo. A ressalva, como em alguns níveis seguintes, ocorre para R3 em $A$, onde pode ocorrer aumento de $P$ e diminuição de S. Para Piaget (1995), não se trata de compensação das variáveis envolvidas, mas apenas de uma aceitação das aparências, sem busca de coerência. Vejamos alguns exemplos encontrados em nossos protocolos:

ELI (15;9): Em A, S e P aumentam para R1 e diminuem para R2. Em R3 para S, diz: diminuiu mais o quadradinho. Em que parte? Em relação às partes aqui do lado (largura) diminuiu pra caramba. Em B: P aumenta em R1 e S continua igual: Por quê? Porque talvez... a forma do quadrado, só mudou de forma, mas o diâmetro do comprimento dentro do quadrado não. Em R2, $\mathrm{P}$ e S permanecem iguais e, em R3, $\mathrm{P}$ e S aumentam.

No nível IB, as correspondências globais, fruto de abstrações empíricas são menos empregadas pelo sujeito que apresenta tentativas de compensação. Assim, temos soluções mistas e variações entre aumentos e diminuições. É o caso de:

JES (15;3): Em B, admite que S e P não variam para R1. Em R2, para P: Dá impressão que andou mais porque você esticou e ficou mais comprido o caminho. E o cupim ${ }^{5}$, comeu menos, comeu mais ou comeu a mesma coisa? A mesma coisa, porque só afinou, se juntar tudo é a mesma coisa.

$\operatorname{ALE}(21 ; 3)$ : Em A, R2: A formiga anda mais, menos ou igual ao que ela andava antes? Acho que ela anda a mesma coisa. A mesma coisa, por que? Aumentou a largura, mas o comprimento diminuiu. Eu acho que é o mesmo tamanho dos outros. E em relação à parte de dentro, ao cupim? Acho que a mesma coisa também. Por quê? Porque é o mesmo tamanho, só ficou mais comprido... a largura, mas o comprimento diminuiu, mas acho que é o mesmo tamanho das anteriores. Por dentro também é a mesma coisa? Por dentro também. Em R3, P: eu acho que ela anda menos. Por quê? Apesar do comprimento ter aumentado, a largura diminuiu, acho que anda menos que nos outros.

No nível IIA, as respostas corretas começam a se impor e isso é notadamente percebido pela conquista da conservação do perímetro em $\mathrm{A}$ e da área em $\mathrm{B}$. Este fato não ocorria nos níveis anteriores. Piaget (1995, p. 198) explica:

\begin{abstract}
É necessário, pois, admitir que esta invariabilidade de comprimento do 'mesmo barbante' é assegurada por coordenações de não-diferenciação das numerosas conservações, iniciadas no nível IIA, fundadas sobre as identidades, reversibilidades e compensações habituais. Acontece o mesmo com a conservação da superfície em $B$, quando dos deslocamentos dos oito elementos com os quais é formado o quadrado inicial. De maneira geral, a abstração reflexionante, em jogo nestas reações, consiste em tirar das coordenações em questão, uma lei de 'comutabilidade' (ou comutatividade no sentido amplo) segundo a qual o que é acrescentado num ponto (aqui, o comprimento) corresponde, quantitativamente, ao que é retirado em um outro (neste caso, a largura).
\end{abstract}

Há uma inspeção perceptiva fundada em abstrações empíricas, porém, ao ser capaz de considerar, sobretudo em B, o aumento do perímetro e a manutenção da área, tem-se uma abstração reflexionante que, por ser apoiada nos objetos, carrega o nome de abstração pseudoempírica.

O processo de reconstituição, apontado anteriormente, permite ao sujeito repensar o que acabou de dizer. Isso fica claro quando, ao final das transformações em cada dispositivo, solicitamos que seja feito um resumo sobre o que acabou de ocorrer.

Quando os termos "área" e "perímetro" não eram compreendidos pelos participantes, foram substituídos pela ideia de uma formiga que caminhava no contorno da figura $(P)$ e pela ideia de um cupim que comia o que ficava na parte interna dessa mesma figura (S).

Cad. Pesq., São Luís, v. 26, n. 3, p. 49-67, jul./set., 2019. 
Assim, observamos em THA $(18 ; 11)$ a necessidade de pegar os pedaços de madeiras e nos provar (ou provar a si mesmo) a conclusão a que acabou de chegar, realizando abstração reflexionante do tipo pseudoempírica:

THA (18;11): Resume, então, o que aconteceu aqui (B). Pega todas as madeiras e as recoloca na posição inicial e vai descrevendo, a cada transformação, como $\mathrm{P}$ aumenta e $S$ se mantém igual.

OLE (15;8): Admite a igualdade para P e S em A em função do tamanho do cordão permanecer sempre o mesmo. Em R3, acredita que S diminui. O perímetro (!) é bem estreito. Será que ele comeu menos só dessa vez ou ele vinha comendo menos? Acho que só dessa vez. Para $\mathrm{B}, \mathrm{P}$ aumenta e $\mathrm{S}$ permanece igual em todas as transformações.

\section{Vejamos KET (18;8):}

Em A, após oscilar entre aumentos e diminuições para $P$ e usar as mãos para tentar medir, responde para R3: O cupim come menos porque o espaço é bem pequenininho, mas agora o que eu pensei aqui que a formiga anda sempre o mesmo pelo tamanho do cordão, né? O contorno é sempre o mesmo. Desde antes ou só agora? Não, em todos, ela anda o mesmo tanto. Porque o cordão é o mesmo, não muda. [...] Em B, assume que $\mathrm{S}$ sempre é a mesma, pois: só mudou o formato, porém continuou a mesma massa. Não tirou nenhum, continua todos aqui, só de forma diferente, então acho que é a mesma coisa.

O nível IIB apresenta uma curiosidade, observada nos protocolos piagetianos; tratase de uma conservação geral, tanto para $\mathrm{P}$ como para $\mathrm{S}$, em todas as transformações, exceto (mas não sempre) para R3 em A.

JES (18;11): Em A, R1: O perímetro aumentou, diminuiu ou está igual? O perímetro é o mesmo. Por quê? Porque é o mesmo fio que eu estou usando para conectar os pininhos. E a área está menor, está maior ou é a mesma quantidade? Eu acho que é igual. Por quê? Eu acho que é igual porque o perímetro que tá demarcando a área... o comprimento do perímetro é o mesmo. O fiozinho que está passando no perímetro é o mesmo, acredito que a área deve ser a mesma. Em R2: o perímetro é o mesmo porque eu ainda continuo usando a mesma fitinha para marcar os pontinhos. E a área? Eu acho que ela é igual, porque o fiozinho do perímetro ainda é o mesmo, vai aumentar na largura, mas vai diminuir no comprimento aqui do lado. R3: Perímetro é o mesmo porque continua sendo a mesma fitinha. E a área? Acho que é menos. Por quê? Porque que eu me lembre acho que a área é um lado vezes o outro. Se tivesse $1 \mathrm{~cm}$ aqui (aponta para a largura) e uns $20 \mathrm{~cm}$ aqui (aponta para o comprimento), acho que não é a mesma área que tinha antes. E você acha que é menor só aqui ou antes também? Só nesse. Antes você acha que é igual? Sim. Ao resumir, repete o que disse. Então a área vem igual até aqui e, aí, ela fica menor? Acho que não, acho que falei bobeira. Eu acho que a área é a mesma porque vai ser o mesmo espaço que o perímetro tá marcando. Essa área (R3) é a mesma de quando estava aqui (R2), estava aqui (R1)? Isso. É igual? Sim. Por que você acha agora que é igual? Porque eu acho que ela está mais fininha, mas por outro lado ela está mais comprida. Antes ela era mais larga e menos comprida. Em B: O perímetro é igual porque eu só mudei as madeirinhas de lugar. O que tava aqui em cima eu coloquei aqui do lado, antes ela tava mais quadradinha, agora ela tá mais retangular. Ela perdeu de altura, mas ela ganhou de largura aqui. E a área? Maior, menor ou igual? Igual. Por quê? Porque a área que tinha aqui passou pra cá e aí ficou igual a de antes, o mesmo tamanho do espaço. Mesmas respostas para R2 e R1.

O aspecto curioso desse nível é compreender que ele é considerado por Piaget (1995) como um avanço em relação aos precedentes em função da ação da abstração reflexionante que conduz, nesse caso, ao erro. A este respeito, o autor aponta:

Pode-se, pois, dizer que, em seu princípio, a abstração que inspira os sujeitos é correta, mas que a dupla aplicação imaginada por eles exigiria, além do controle 
dos fatos (sempre necessário para estabelecer se tal modelo dedutivo, válido em si mesmo, é ou não aplicável a este ou aquele setor da realidade), uma reflexão de um nível superior, ou reflexão 'sobre' as reflexões anteriores, de modo a examinar se este acúmulo de duas conservações é coerente ou se elas são incompatíveis (PIAGET, 1995, p.199).

JUS (21;5): Em B/R3: S permanece o mesmo, mas para P, pensa demoradamente e diz: Acho que agora ela anda mais... como que pode isso, confunde... (risos). Por que ela anda mais? Acho que, fisicamente falando, tem que ser a mesma coisa, não tem como andar mais. Só que dá muito a impressão que é mais... porque é o mesmo tanto de madeira. O que é fisicamente falando? Tipo, apesar de ter mudado o jeito que tava, é a mesma quantidade sempre. Só que olhando assim, dá muito a impressão de que ela tá andando mais. É a mesma quantidade de? Madeira, então continua a mesma quantidade das voltas (!). Não sei dizer.

O nível III é o das respostas corretas, vejamos o exemplo a seguir:

JEQ (21;5): Em A, apresenta condutas como no nível precedente, admitindo uma conservação dupla para S e P. Porém, em R3, acredita que S está bem menor. Não é a mesma coisa. É menor. Por quê? Porque olhando assim a gente não consegue acreditar que é o mesmo. Os outros próximos, por não ter tanta diferença de altura e largura parece ser a mesma coisa. Mas será que é, será que não é... [...] E você acha que ele come menos só aqui e antes é igual? Não, não é igual. Recorre a abstrações pseudoempíricas recolocando a corda em torno dos pinos várias vezes, medindo com os dedos e com as palmas das mãos. Não é a mesma coisa, vai mudando, não vai dar a mesma quantidade. Em relação à formiga ou ao cupim? Ao cupim. Você acha que acontece o que com a quantidade? Vai diminuindo, porque a distância diminui de um ponto a outro. Em B, S se conserva e P sempre aumenta.

O desempenho dos nossos sujeitos na Prova Operatória das Relações entre Superfícies e Perímetros dos Retângulos, conteúdo por meio do qual o mecanismo das abstrações pode ser observado, está apresentado na tabela 2, a seguir:

Tabela 2 - Desempenho dos Participantes na Prova Operatória

\begin{tabular}{ccc}
\hline Idades & $\begin{array}{c}\text { Níveis de } \\
\text { Compreensão }\end{array}$ & Frequência absoluta \\
\hline 15 anos & IA & 3 \\
15 anos & IB & 3 \\
15 anos & IIA & 2 \\
15 anos & IIB & - \\
15 anos & III & - \\
18 anos & IA & - \\
18 anos & IB & 4 \\
18 anos & IIA & 3 \\
18 anos & IIB & 3 \\
18 anos & III & - \\
21 anos & IA & 3 \\
21 anos & IB & 2 \\
21 anos & IIA & 3 \\
21 anos & IIB & 2 \\
21 anos & III & 30 \\
\hline Total & & \\
\hline
\end{tabular}

Fonte: Elaborado pelas autoras.

A análise das correlações de Spearman, que permitiu identificar as relações entre a construção das noções de guerra e paz e a prova apresentada por meio da qual as abstrações foram identificadas, foi realizada no Programa ACTION. O nível de significância adotado é de $95 \%$, ou seja, se $p<0,05$, aceita-se a hipótese de que existe 
correlação entre os fatores analisados, ao passo que, se $p=0,05$ ou $p>0,05$, tem-se uma relação estatisticamente não-significante.

Conforme indicado na tabela 3 , a seguir, obteve-se uma correlação positiva de índice elevado entre a noção social, assim como da construção de relações espaciais, nas quais também foi possível observar a abstração reflexionante. Entende-se que, conforme evolui, mediante coordenações de ações, a capacidade de construir relações espaciais, aumenta o nível de compreensão das noções de guerra e paz. Isto porque a construção de relações espaciais e a construção de relações entre guerra e paz têm em comum o processo de abstração reflexionante.

$\begin{gathered}\text { Tabela } 3 \text { - Resultados das correlações de Spearman realizadas entre os níveis de } \\ \text { guerra e paz e a prova que revela o mecanismo da abstração }\end{gathered}$
Prova Operatória

\section{DISCUSSÃO}

Em relação à construção do conhecimento social, observamos que, mesmo elevando a faixa etária dos nossos participantes, comparada àquela utilizada nos estudos brasileiros realizados anteriormente e, sobretudo, nos estudos internacionais, o atraso na construção de noções mais elaboradas ou de nível III se manteve. Dessa forma, mesmo em alunos mais velhos, observamos uma grande dificuldade na elaboração de interpretações menos aparentes e estereotipadas. A importância na condução de estudos sobre o conhecimento social reside justamente em acompanhar as explicações que os sujeitos constroem e, como Delval (2007) alerta, atentar para o fato de que concepções mais rígidas e simplistas podem determinar ações/maneiras de interagir que também acabam sendo rígidas e simplistas.

Um acontecimento como a guerra foi interpretado pela maioria de nossos participantes sob a ótica da aparência, do aspecto militar, etc. Aquilo que fugia ao aparente, que necessitava de uma análise mais profunda, tais como a economia, a cultura, a história e tantos outros aspectos que afetam direta ou indiretamente os membros de uma sociedade e a existência de um conflito, escapou à interpretação de nossos participantes. Como nos diz Ramírez (2008), numa guerra intervém uma grande multiplicidade de variáveis e sua existência não responde a uma única causa. A análise e a compreensão desse fenômeno solicitam enfoque multidisciplinar.

De igual modo, se apresenta a questão da paz para nossos participantes, vista muito mais dependente de ações isoladas e pessoais do que envolvendo negociações mais amplas, tratados, políticas de direitos humanos e desarmamento, entre tantos outros elementos. Como salienta Ramírez (2008), pensar na paz requer contribuições de diferentes campos científicos.

No início do presente artigo, ressaltamos que, no aporte teórico-metodológico da Epistemologia Genética, as relações de interdependência explicam a construção do conhecimento. Assim, as correlações entre as abstrações reflexionantes, o acesso às informações advindas do social, os processos maturacionais dos sujeitos e os mecanismos reguladores da equilibração constituem um todo indissociável que permite as generalizações a patamares mais evoluídos de organização interna e, consequentemente, leitura mais aprimorada da realidade social.

Os dados que apresentamos exemplificam essa relação, visto que evidenciam um processo que não se concretizará apenas por fator maturacional, caso contrário, pela idade dos participantes, teríamos mais crenças caracterizadas como de nível III. Indicam, ainda, que a condição de respostas de nível mais elaborado de construção de uma dada noção social também não é garantida apenas por acesso a informações acerca do tema, uma vez que as noções de guerra e paz compõem o cenário mundial 
atual e são acessadas continuamente pelos participantes do estudo. A reflexão sobre a informação, a análise de sua fonte e tantas outras variáveis interferem, e muito, na interpretação de um fenômeno social.

A correlação significativa entre as variáveis pesquisadas nos mostrou que, à medida que avança a compreensão na Prova Operatória das Relações entre as Superfícies e Perímetros dos Retângulos, avançam as concepções sobre guerra e paz. Ou seja, o avanço na construção desse importante mecanismo, motor do desenvolvimento cognitivo, favorecendo construções novas e generalizadoras, possibilita o avanço na construção do conhecimento social.

\section{CONSIDERAÇÕES FINAIS}

Ao analisarmos a construção do conhecimento social para compreender como o pensamento evolui na tentativa de interpretar o mundo, percebemos, por meio do estudo realizado, que há a necessidade de intervenção do processo de abstração reflexionante nas atividades cognitivas do sujeito; processo que se realiza pela retirada de certos caracteres, utilizando-os para outras finalidades. Dessa forma, podemos analisar os elementos que compõem as interpretações sobre o mundo social como necessários aos processos, entre si complementares, denominados na teoria piagetiana de reflexionamento e reflexão. Assim, os sujeitos entram em contato com as normas e informações sociais, mas, para construírem noções sociais mais elaboradas, mediante transformações e reorganizações, necessitam relacionar esses elementos com novas construções, num exercício que transpõe e reconstrói, num plano superior - o da reflexão -, o que provém de um plano inferior. Esse processo, a nosso ver, permite ao sujeito atribuir sentido às informações por meio da coordenação das ações, ou seja, internamente.

Tomando por base nossos dados, uma preocupação se apresenta: como esses jovens e adultos compreenderão as instituições econômicas e políticas? Como podem conduzir ações que envolvam a necessidade de uma visão menos simplista dos fenômenos sociais? Não seria possível inferir, a esse respeito, que ideias carregadas de pouca complexidade dificultariam ações e interpretações em que a coordenação de diferentes elementos e perspectivas seja algo necessário? Isto, a nosso ver, é uma característica presente nas interações atuais em relação a inúmeros assuntos do mundo social. Se, por um lado, não basta que as informações sejam dadas ao sujeito para que as incorpore, por outro, sem elas não há elaboração interna. É preciso reconhecer a relevância de processos interventivos promotores de reflexão, de trabalho intelectual a partir de vivências, experiências sociais, debates, contradições do pensamento, levantamento e testagem de hipóteses, solução de conflitos cognitivos e afetivo-sociais próprios das relações humanas.

Em tempos de grande acesso a informações, veiculadas de diferentes formas e por veículos de comunicação variados, é importante estar atento a que e como a população as interpreta; que leitura consegue fazer; que relações estabelece e como pode ter uma compreensão mais crítica dos diferentes fenômenos sociais. A formação desse modo de olhar o mundo inicia-se muito antes de o indivíduo tornar-se adulto, e a educação desempenha um papel fundamental nesse processo. A ausência de compreensão da totalidade social conduz a soluções impactantes e unilaterais, que desconsideram a conjuntura e a história na produção dos fenômenos sociais.

Como implicação pedagógica, a pesquisa realizada produziu reflexão acerca da ausência de balanço entre o acesso à informação e o processo de construção de conhecimento na escola. Nossos dados evidenciaram que aos sujeitos não basta ter acesso à informação (mesmo quando isso corre de forma correta, ou seja, quando se pode perceber que existia um dado coerente com o que se veiculava no mundo social), mas é preciso saber depurá-la e investigá-la de forma contextualizada. A escola é o 
espaço privilegiado para que esse modo pensante seja desafiado e valorizado de tal forma que se reconheça o lugar dela na emancipação e na construção da cidadania.

\section{REFERÊNCIAS}

ARAÚJO, A. S.; GOMES, L. R. G. A noção de mobilidade social em adolescentes. Educar em Revista, Curitiba, n. 38, p. 193-204, 2010.

ASSIS, O. Z. M. Conhecimento físico, conhecimento lógico-matemático e conhecimento social. In: ASSIS, M.; ASSIS, O. (Org.). PROEPRE: Fundamentos Teóricos e Prática Pedagógica para a Educação Infantil. $7^{a}$ ed. Campinas: Gráfica FE/LPG, 2013. p.93-126.

BARROSO, L. M. S. As ideias das crianças e adolescentes sobre seus direitos: um estudo evolutivo à luz da teoria piagetiana. 2000. 327 f. Dissertação (Mestrado em Educação) Faculdade de Educação, Universidade Estadual de Campinas, Campinas, SP, 2000.

CANTELLI, V. C. B. Um estudo psicogenético sobre as representações de escola em crianças e adolescentes. 2000. 227 f. Dissertação (Mestrado em Educação) - Faculdade de Educação, Universidade Estadual de Campinas, Campinas, SP, 2000.

DELVAL, J. La representación infantil del mundo social. In: TURIEL, E.; ENESCO, I.; LINAZA, J. (Org.). El mundo social en la mente del niño. Madrid: Alianza, 1989. p. 245-328.

DELVAL, J. Introdução à prática do método clínico: descobrindo o pensamento da criança. Tradução de Fátima Murad. Porto Alegre: Artmed, 2002.

DELVAL, J. Aspectos de la construcción del conocimiento sobre la sociedad. Educar em revista, Curitiba, n. 30, p. 45-64, 2007.

DELVAL, J. El descubrimiento del mundo económico por niños y adolescentes. Madrid: Morata, 2013.

DELVAL, J.; DEL BARRIO, C. Las ideas de los niños acerca de la guerra y la paz. In: MARTíN, F.; BURILLO, F. (Coord.). La guerra: realidad y alternativas. Madrid: Complutense, 1992. p. $165-175$.

DELVAL, J.; ECHEÍTA, G. La comprensión en el niño del mecanismo de intercambio económico y el problema de la ganancia. Infancia y Aprendizaje, España, n. 54, p. 71-108. 1991.

DELVAL, J.; VILA, I. Los niños y Dios - ideas infantiles sobre la divinidad, los orígenes y la muerte. México: Siglo Veintiuno, 2008.

DENEGRI, M; DELVAL, J. Concepciones evolutivas acerca de la fabricación del dinero. I. Los niveles de comprensión. Investigación en la escuela, España, n. 48, p. 39-54. 2002.

ENESCO, I. et al. La comprensión de la organización social en niños y adolescentes._Madrid: CIDE, 1995.

FAGUNDES, A. J. F. M. Descrição, definição e registro de comportamento. São Paulo: Edicon, 1981.

HERNÁNDEZ, J. A. Y. Las guerras en la mente del niño: La participación de la comunicación publica en su construcción. REIS: Revista Española de Investigaciones Sociológicas, Madrid, n. 57, p. 179-189, jan. /mar. 1992.

MANO, A.; SARAVALI, E. G. As relações entre a construção da abstração reflexionante e o conhecimento social: um estudo psicogenético. Revista de Educação Pública, Cuiabá, v. 23, n. 54, p. 759-779, set/dez, 2014. 
MONTEIRO, T. A. A construção da noção de violência em crianças e adolescentes inseridos em diferentes contextos. 2013. 162 f. Dissertação (Mestrado em Psicologia) - Instituto de Psicologia, Universidade Estadual de São Paulo, São Paulo, 2013.

NAVARRO, A.; ENESCO, I. ¿Por qué hay guerras? La representación de los conflictos sociales en los niños. Signos - Teoría y práctica de la educación, [s. I.], n. 10, p. 54-61, 1993.

PIAGET, J. O raciocínio na criança. Tradução de Valerie Rumjaneck Chaves. Rio de Janeiro: Record, 1967.

PIAGET, J. A Epistemologia genética, sabedoria e ilusões da filosofia - problemas de epistemologia genética. São Paulo: Abril Cultural, 1978. (Coleção: Os pensadores.).

PIAGET, J. A representação do mundo na criança. Tradução Rubens Fiúza. Rio de Janeiro: Record, 1979.

PIAGET, J. (coord.). Abstração reflexionante - relações lógico-aritméticas e ordem das relações espaciais. Tradução de Fernando Becker e Petronilha Beatriz G. da Silva. Porto Alegre: Artmed, 1995.

PIAGET, J. As formas elementares da dialética. Tradução de Fernanda Mendes Luiz. São Paulo: Casa do Psicólogo, 1996.

PIECZARKA, T. Concepções de desigualdade social e mobilidade socioeconômica de adolescentes de escola pública de Curitiba. 2009. 255 f. Dissertação (Mestrado em Educação) - Universidade Federal do Paraná, Curitiba, 2009.

RAMIREZ, A. J. R. Guerra y paz. Revista Mexicana de Sociología. Ciudad de Mexico, n. 3, p. 589-617, jul./sep. 2008.

SOUZA, E.P.; SARAVALI, E.G. As relações entre o raciocínio lógico-matemático e a construção do conhecimento social: um estudo evolutivo. Cadernos de Educação, Pelotas, n. 53, p. 101122, 2016. 